\title{
Dystrophy of the Great Toenail by Subungual Exostosis and Hyperostosis: Three Case Reports with Different Clinical Presentations
}

\author{
Uwe Wollina ${ }^{a}$ Robert Baran ${ }^{c}$ Jacqueline Schönlebe ${ }^{b}$ \\ a Department of Dermatology and Allergology and 'Institute of Pathology 'Georg Schmorl', Academic Teaching \\ Hospital Dresden-Friedrichstadt, Dresden, Germany; ${ }^{C}$ Nail Disease Centre, Cannes, France
}

\section{Key Words}

Nail surgery $\cdot$ Subungual exostosis $\cdot$ Hyperostosis $\cdot$ Bone $\cdot$

Nail tumors · Pain · Malalignment of the great toenail

\begin{abstract}
Subungual exostoses and hyperostoses of the great toenail are a differential diagnosis of nail tumors. We present 3 cases of subungual exostosis/hyperostosis with secondary nail dystrophy: a 36- and a 37-year-old woman as well as an 8 -year-old boy. Two of the 3 patients suffered from pain. The 2 female patients presented with the classic dorsolateral firm protrusion, while the child presented with bilateral nail dystrophy with lateral wall hypertrophy. In this later case, a bony ridge was identified, which is an unusual subungual, nonprotruding type of exostosis. The hypertrophic lateral walls were removed by the Vandenbos technique. In the 2 former cases, complete excision of the bony lesions was performed with a proximal block. Healing by second intention was uneventful.

(C) 2016 S. Karger AG, Basel
\end{abstract}

\section{Introduction}

Subungual tumors are seen infrequently, and a definite diagnosis is often possible only after histopathologic examination. They may arise from keratinocytes, melano- cytes, fibroblasts, vasculature, adipocytes, bone, and cartilage $[1,2]$.

First described by Dupuytren [3] in 1847, subungual exostosis reflects a benign hyperostotic osteocartilaginous tumor firmly attached to the bone of the distal phalanx. The tumor grows slowly. Between 16 and 55\% of patients are younger than 18 years of age, the female to male ratio is $2: 1$, and it most often affects the great toe. Secondary nail plate dystrophy is a common feature. Among all patients, about $10 \%$ present with nail dystrophy. Pain is not uniformly present $[4,5]$. On histology, subungual exostosis is composed of trabecular bone covered by a fibrocartilaginous cap [6]. Whether or not subungual osteochondroma is a different entity is still not clear, although it is clearly an exogenous hyperostotic formation.

We report 3 patients with a subungual tumor of the great toe and distortions of the nail plate.

\section{Case Reports}

Cases were selected from the files of our Department from 2001 to June 2015. The permission to photograph has been obtained.

Case 1

A 36-year-old woman presented with a firm subungual swelling of the right great toe. The lesion had developed over a period of 1.5 years; it was initially asymptomatic, but became painful with time.

\section{KARGER 125}

(c) 2016 S. Karger AG, Base

2296-9195/16/0014-0213\$39.50/0

E-Mail karger@karger.com

www.karger.com/sad
Prof. Dr. U. Wollina

Department of Dermatology and Allergology

Academic Teaching Hospital Dresden-Friedrichstadt

Friedrichstasse 41, DE-01067 Dresden (Germany)

E-Mail wollina-uw@khdf.de 

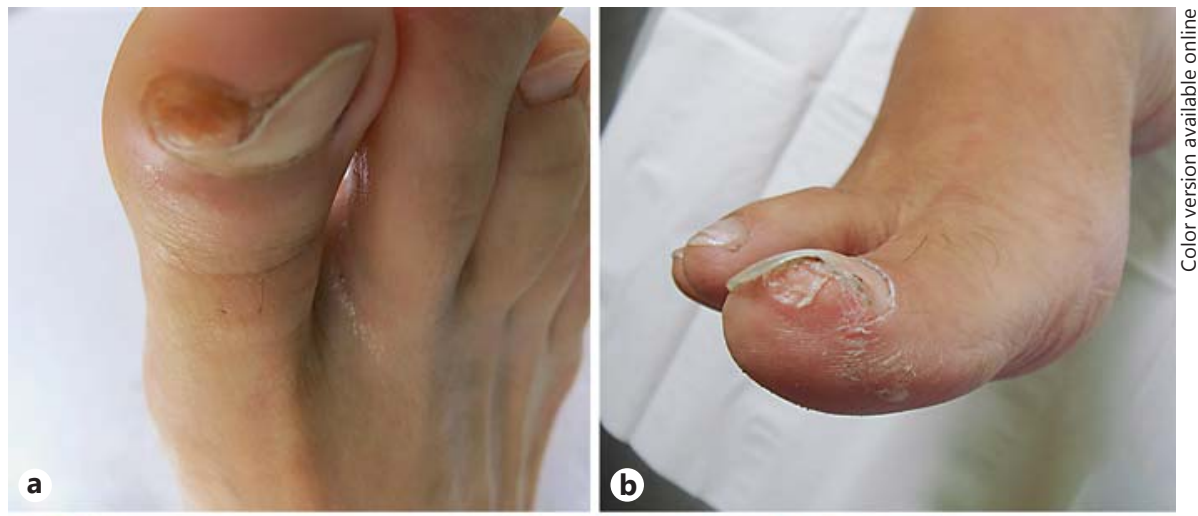

Fig. 1. Extruding type of subungual exostosis. a Clinical presentation of case 1. b Clinical presentation of case 2. c After nail avulsion, an ovaloid tumor is visible (case 1). d After complete excision of the tumor (case 1).
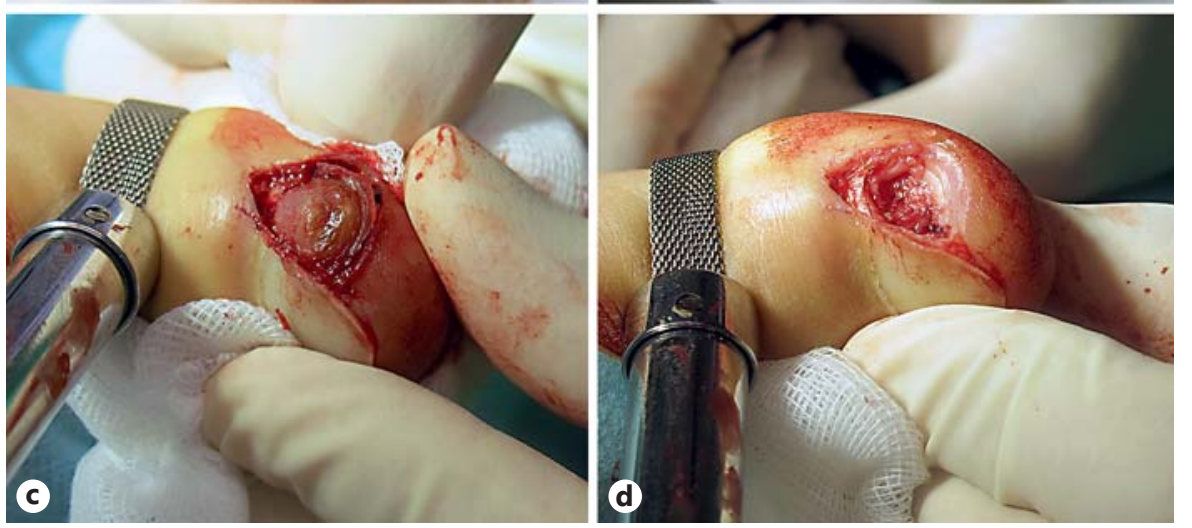

On examination, we observed a firm subungual tumor beneath the medial part of the great toenail with disfiguration of the nail plate, consisting of a smooth surface, a hypercurvature of the proximal portion, and a loss of the distal portion (fig. 1a). Surgery was advised.

Nail surgery was performed with regional anesthesia and a proximal toe block (fig. 1c, d). Partial avulsion of the medial nail part was performed using a nail plate elevator. After partial removal of the nail plate by a scissor, a bony round tumor was found firmly attached to the distal phalanx. It was removed by a rasparator. The tourniquet was removed, and hemostasis was achieved by bipolar forceps. Leukase $\mathrm{N}$ cones (framycetin sulfate plus lidocaine hydrochloride; Dermapharm, Grünwald, Germany) were placed into the wound. Healing by second intention lead to an uneventful wound closure. Histopathology revealed mature trabecular bone with a fibrocartilaginous cap characteristic of subungual exostosis (fig. 2).

\section{Case 2}

A 37-year-old woman presented with an asymptomatic mediodistal swelling of the great toenail of her right foot. The process had developed slowly over 12 months. Her primary complaint was the nail plate distortion (fig. 1b). An X-ray confirmed the suspicion of subungual exostosis, and surgical treatment was performed as described.

\section{Case 3}

An 8-year-old boy with bilateral ingrown great toenails presented complaining of slow-growing, hard nail plates.

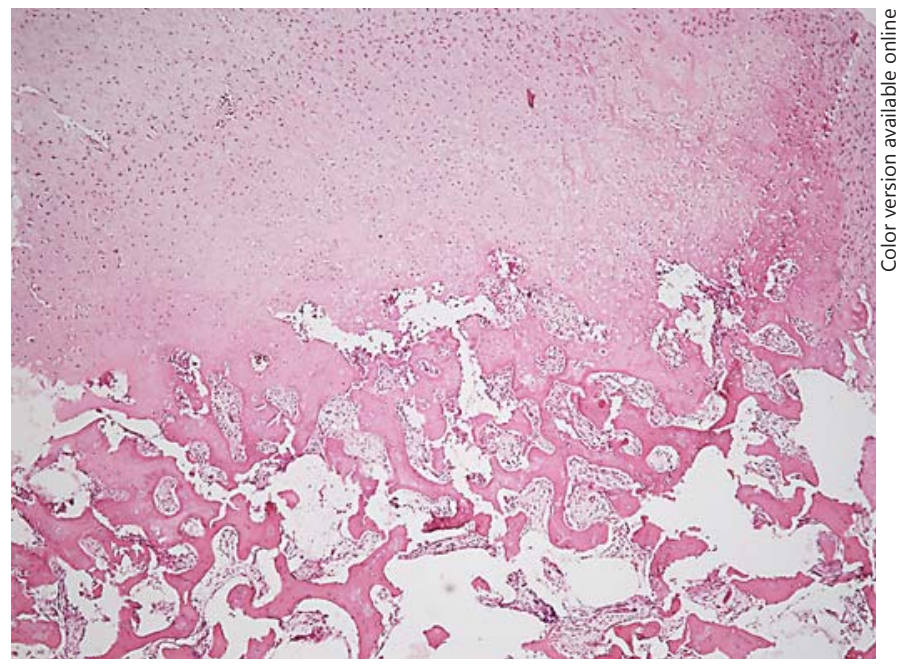

Fig. 2. Histopathology of case 1 with mature trabecular bony structures. Hematoxylin-eosin. $\times 10$.

On examination, oyster shell nail plates were found, and, therefore, pachyonychia (the noncongenital type) was suspected. Nail pressure was painful, and hypertrophic lateral walls were noted (fig. 3a). The triangular shape of the nail plates and their lateral deviation suggested a malalignment of the great toenails. Surgery 

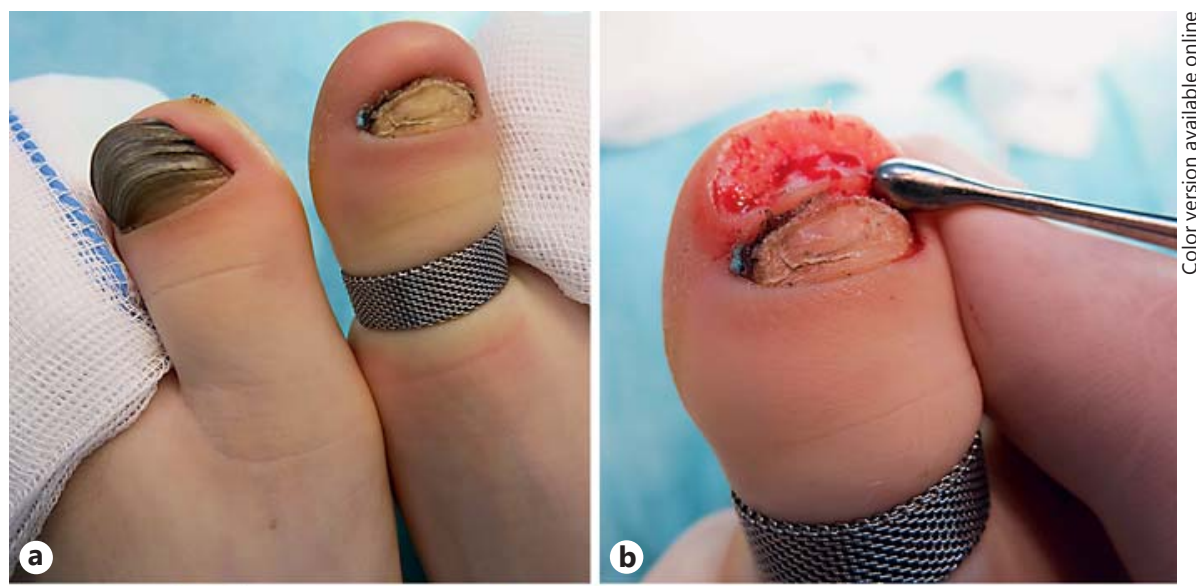

Fig. 3. Case 3. a Oyster shell nail plates and malalignment of the great toenails. b Wedge excision. c, d With a bony ridge (arrows), i.e. nonprotruding exostosis/hyperostosis.
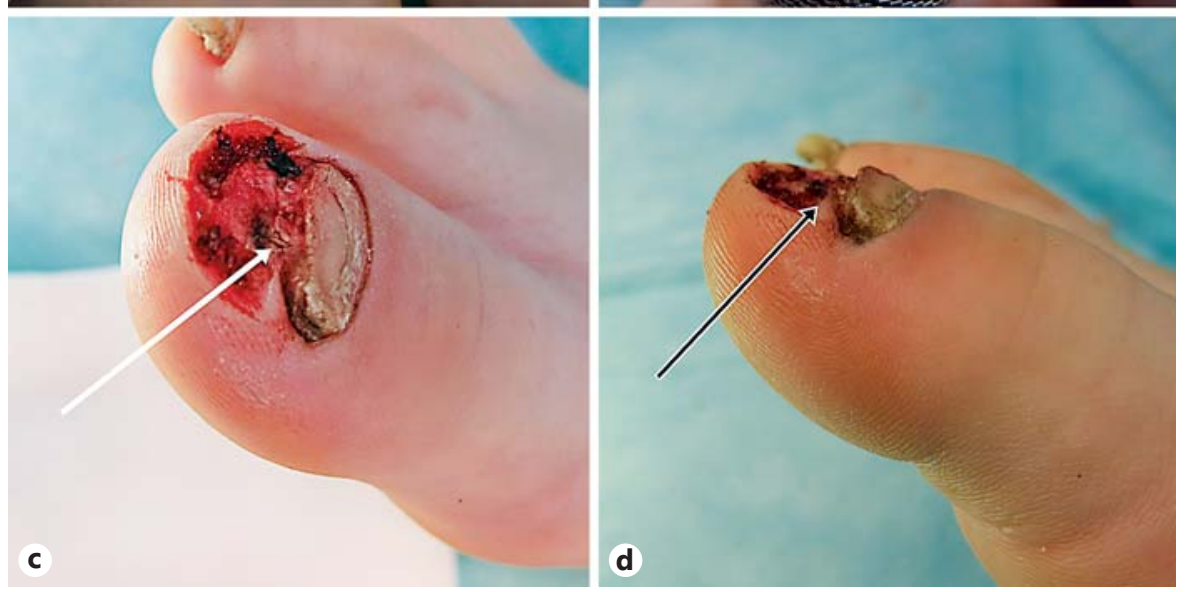

was advised. The classical approach to malalignment by ungueodermal flap was not chosen because of the ingrown nails and the patient's age [7].

Surgical procedure was performed with a distal block and a tourniquet (fig. 3b-d). After distal nail plate avulsion, we discovered a bony ridge parallel to the hyponychium. This was removed by a rasparator. Hypertrophic lateral walls were removed by the Vandenbos procedure, with generous removal of soft tissue [8]. The wounds were covered with povidone-iodine ointment and gauze. Healing by second intention was uneventful. Histopathologic examination revealed mature trabecular bone with a fibrocartilaginous cap, and the diagnosis of subungual exostosis was confirmed.

\section{Discussion}

Subungual exostosis is a common benign tumor predominantly occurring at the great toenail. Exostosis consists of mature trabecular bone, and it is part of the spectrum of hyperostotic bone formation. Here, we show two different clinical presentations: the classic unilateral mediodorsal protruded type and a unique nonprotruded bilateral type beneath the nail bed [9]. Trauma has been associated with the formation of subungual exostosis, although this could not be confirmed in our patients [10].

The nail plate develops from proximal and distal nail matrices. Human studies on great toenails suggested that the nail bed contributed to $21 \%$ of the nail plate thickness. After avulsion, the longitudinal ridges of the nail are visible in the nail bed. The bony part of the phalanxes is important for regular nail plate growth [11]. If bony irregularities affect the nail bed, this will change the growth pattern and nail thickness, as evident in case 3. If the oyster shell-like appearance of the nail is caused by the bone process or by malalignment of the great toenails is a matter of discussion [7, 12]. Case 3 differs from cases 1 and 2 by the presence of a bony ridge formation rather than the classic exostosis caused by a circumscribed oval process. Case 3 had no other signs of hyperostosis syndromes related to genetic or metabolic aberrations. Histology did not differ from cases 1 and 2. Therefore, case 3 can be interpreted as a nonprotruding type of exostosis/hyperostosis. 
Subungual exostosis has a wide range of differential diagnoses. Since both case 1 and case 2 suffered from pain, osteoid osteoma, a benign tumor of the bony tissue, is an important differential diagnosis. The term 'osteoid osteoma' was coined by Henry L. Jaffe [13] with the following clinical characteristics:

- Younger age (in his paper, adolescents and young adults)

- Local pain which worsens at night

- Localization in an area of spongy bone never penetrating the periosteum

- Roentgenographically round, clearly circumscribed lesions

- Not larger than $2 \mathrm{~cm}$ in diameter

This tumor rarely affects fingers and toes. In cases where it does, distortions of nail plate morphology may be the result [14]. Osteoid osteoma of the great toe is a very rare observation $[14,15]$.

Other differential diagnoses of subungual exostosis include onychomatricoma [16], osteosarcoma [17], chondrosarcoma [18], chondromyxoid fibroma [19], Ewing's sarcoma [20], liposarcoma [21], giant cell tumor [22], subungual amelanotic melanoma [23], and digital mucoid pseudocyst [24].

The treatment of choice is surgical excision. However, recurrence rates of $14.3 \%$ [25] to 53\% [26] have been reported. Excision of the entire lesion including the fibrocartilaginous cap is crucial to avoid local recurrences. Also, particular care has to be taken to preserve the nail matrix [27]. In cases 1 and 2, complete excision was performed followed by healing by second intention. In case 3 , a fish mouth-like incision was impossible, because the bony ridge spanned the entire width of the distal nail bed. Therefore, a distal nail avulsion was combined with careful removal of the bone by a rasparator.

\section{Statement of Ethics}

Patients were treated according to the Helsinki protocol.

\section{Disclosure Statement}

The authors have no conflicts of interest to declare.

\section{References}

1 Perrin C: Tumors of the nail unit. A review. Part I: acquired localized longitudinal melanonychia and erythronychia. Am J Dermatopathol 2013;35:621-636.

2 Perrin C: Tumors of the nail unit. A review. Part II: acquired localized longitudinal pachyonychia and masked nail tumors. Am J Dermatopathol 2013;35:693-709.

3 Dupuytren G: On exostosis on the upper surface of the ungula phalanx of the great toe; in Le Gros C (ed): On Injuries and Diseases of the Bones. London, The Sydenham Society, 1847, pp 408-415.

4 DaCambra MP, Gupta SK, Ferri-de-Barros F: Subungual exostosis of the toes: a systematic review. Clin Orthop Relat Res 2014;472: 1251-1259.

5 Davis DA, Cohen PR: Subungual exostosis: case report and review of the literature. Pediatr Dermatol 1996;13:212-218.

6 Jetmalani SN, Rich P, White CR Jr: Painful solitary subungual nodule. Subungual exostosis (SE). Arch Dermatol 1992;128:849, 852.

7 Baran R, Haneke E: Etiology and treatment of nail malalignment. Dermatol Surg 1998;24: 719-721.

8 Vandenbos KQ, Bowers WF: Ingrown toenail: a result of weight bearing on soft tissue. US Armed Forces Med J 1959;10:1168-1173.

9 Başar H, Inanmaz ME, Başar B, Bal E, Köse KÇ: Protruded and nonprotruded subungual exostosis: differences in surgical approach. Indian J Orthop 2014;48:49-52.
10 Letts M, Davidson D, Nizalik E: Subungual exostosis: diagnosis and treatment in children. J Trauma 1998;44:346-349.

11 de Berker DA, André J, Baran R: Nail biology and nail science. Int J Cosmet Sci 2007;29: 241-275.

12 Wollina U, Wollina K: Growth malalignment of the great toenails: a cause of chronic relapsing paronychia in infants. Z Hautkr 1995;70: 35-37.

13 Jaffe HL: 'Osteoid-osteoma' - a benign osteoblastic tumor composed of osteoid and atypical bone. Arch Surg 1935;31:709-728.

14 Turkmen I, Alpan B, Soylemez S, Ozkan FU, Unay K, Ozkan K: Osteoid osteoma of the great toe mimicking osteomyelitis: a case report and review of the literature. Case Rep Orthop 2013;2013:234048.

15 Hattori H, Takase K, Morohashi A: Osteoid osteoma of the great toe. Orthopedics 2011; 34:e432-e435.

16 Tavares G, Di-Chiacchio N, Di-Santis E, Alvarenga L, Stuhr P, de-Farias D, Tosti A, Di-Chiacchio NG: Onychomatricoma: epidemiological and clinical findings in a large series of 30 cases. Br J Dermatol 2015;173:1305-1307.

17 Sproule JA, Kennedy C, Mulcahy DM: Osteosarcoma: a rare cause of painful enlargement of the hallux. Foot (Edinb) 2011;21:201-203.

18 Mondal SK: Chondrosarcoma of the distal phalanx of the right great toe: report of a rare malignancy and review of literature. J Cancer Res Ther 2012;8:123-125.
19 Bahk WJ, Mirra JM, Sohn KR, Shin DS: Pseudoanaplastic chondromyxoid fibroma. Ann Diagn Pathol 1998;2:241-246.

20 Dunn EJ, Yuska KH, Judge DM, Garner FL, Varano LA: Ewing's sarcoma of the great toe. A case report. Clin Orthop Relat Res 1976; 203-208.

21 Daniels J, Green C, Paul A: Liposarcoma of the great toe: a case report. J Foot Ankle Surg 2014;53:493-496.

22 Bachhal V, Rangdal S, Saini U, Sament R: Giant cell tumor of distal phalanx of great toe. A case report. Foot (Edinb) 2011;21:198-200.

23 Arican O, Sasmaz S, Coban YK, Ciralik H: Subungual amelanotic malignant melanoma. Saudi Med J 2006;27:247-279.

24 Karte K, Bocker T, Wollina U: Acquired clubbing of the great toenail. Digital mucoid cyst (pseudocyst). Arch Dermatol 1996;132:225, 228

25 Fikry T, Dkhissi M, Harfaoui A, Adil A, Haddoun A, Zryouil B: Subungual exostoses. A retrospective study of a series of 28 cases. Acta Orthop Belg 1998;64:35-40.

26 Miller-Breslow A, Dorfman HD: Dupuytren's (subungual) exostosis. Am J Surg Pathol 1988; 12:368-378.

27 Suga H, Mukouda M: Subungual exostosis: a review of 16 cases focusing on postoperative deformity of the nail. Ann Plast Surg 2005;55: 272-275. 